\title{
BMJ Open How COVID-19 has affected general practice consultations and income: general practitioner cross-sectional population survey evidence from Ireland
}

\author{
Robyn Homeniuk (D), Claire Collins (D)
}

To cite: Homeniuk R, Collins C. How COVID-19 has affected general practice consultations and income: general practitioner cross-sectional population survey evidence from Ireland. BMJ Open 2021;11:e044685. doi:10.1136/ bmjopen-2020-044685

- Prepublication history and additional supplemental material for this paper is available online. To view these files, please visit the journal online (http://dx.doi. org/10.1136/bmjopen-2020044685).

Received 14 September 2020 Revised 09 March 2021 Accepted 16 March 2021

\section{D) Check for updates}

(C) Author(s) (or their employer(s)) 2021. Re-use permitted under CC BY-NC. No commercial re-use. See rights and permissions. Published by BMJ.

Research Centre, Irish College of General Practitioners, Dublin, Ireland

Correspondence to

Dr Claire Collins;

claire.collins@icgp.ie

\section{ABSTRACT}

Objectives How general practice is delivered in many countries has drastically changed due to the COVID-19 pandemic. This study aimed to answer the question of how general practice has changed in Ireland in response to COVID-19.

Design The Irish College of General Practitioners surveyed its membership before and after the global pandemic hit Ireland using a cross-sectional online survey instrument. Setting This study focuses on primary care, specifically general practice, in Ireland.

Participants In February 2020 before the global pandemic, 526 general practices across Ireland submitted responses to the survey; 538 general practices responded to the second survey during the pandemic in June 2020. This covers $32 \%$ and $33 \%$ of practices in Ireland, respectively.

Main outcome measures The type of consultations by general practitioners (GPs) and practice nurses in both surveys is the main outcome measure reported in this paper. Other changes such as the perceived change in attendance by certain patient groups and practice income are also reported.

Results Face-to-face consultations significantly $(p<0.001)$ decreased from a median of 26 (IQR 21.3-30) to a median of 8 (IQR 6-13). GP telemedicine consultations increased $(p<0.001)$ from a median of 2.4 (IQR $0-5.3$ ) to a median of 11.3 (IQR 6-19). The majority of practices $(80.0 \%)$ reported reduced practice profit. Respondents reported a decline in non-COVID-19-related consultations among certain patient cohorts-92.0\% for children under 6 years old; $79.5 \%$ for patients over 70 years.

Conclusions It is likely that the way general practice is delivered will not return to as it was before the COVID-19 pandemic and increased telemedicine can be expected. However, it is necessary to assess the impact of this shift on patient health and to assess healthcare provider and patient experience to ensure continued high-quality care and patient safety.

\section{INTRODUCTION}

A cluster of 'atypical viral pneumonia' cases was diagnosed in Wuhan City, China in December 2019. ${ }^{1}$ By 9 January 2020, Chinese
Strengths and limitations of this study

- A key strength of this study is the large number of general practitioners who engaged with the surveys. It was possible to survey a third of all practices in Ireland at both time points.

- Due to the large number of responding practices, data cover every county in Ireland in both the preCOVID-19 and during COVID-19 surveys. This and the volume of responses makes our findings more generalisable.

- The timing of the survey was another key strength of the study, as we were able to capture clinical activity data before COVID-19 and then rapidly collect information after the initial wave of the pandemic.

- One of the weaknesses of the study is the design-a self-selecting cross-sectional survey-which could have biased the responses. It was not possible to identify practices and directly match their responses from the first to the second survey.

- Another weakness was that we did not collect sociodemographic information, hence it was not possible to control for deprivation levels and other factors that may affect healthcare utilisation.

authorities found the cause of the outbreak was a novel coronavirus ${ }^{2}$-later named COVID-19. The World Health Organisation (WHO) declared an international public health emergency ${ }^{3}$ and by the end of February 2020, Ireland had its first case. National lockdown measures commenced in March 2020 and recommended that general practitioners (GPs) observe physical distancing, wear personal protective equipment, and use telephone triage and appointments to reduce face-to-face contact. ${ }^{4}$ Epidemiologists globally have been monitoring the progression of this infection while governments have been developing and deploying emergency pandemic responses. The need to have global and national 
emergency management plans has been well documented $^{3}$ since the outbreak of SARS in 2003. Previous outbreaks have proven that contagious diseases can put intense pressure on health systems, especially on general practice, as it is the front line of the medical response. ${ }^{5}$ GPs have expressed their past uncertainty about how to respond to a pandemic. ${ }^{5}$ Indeed, in response to the H1N1 pandemic, primary care staff struggled with implementing new workflows. ${ }^{6}$ In Ireland, comprehensive preparedness plans are in place for handling public health emergencies. These plans follow $\mathrm{WHO}^{7}$ and European Centre for Disease Prevention and Control $(\mathrm{ECDC})^{8}$ guidance and are coordinated by the National Public Health Emergency Team. ${ }^{9}$

GPs in Ireland operate as private professionals charging patients not covered under the public system a fee per visit. The state pays GPs on a capitation basis for patients covered under the public system. Around $43 \%$ of Irish people qualify for free healthcare access either through the public system known as the General Medical Services card $(32.4 \%)$ or a GP-visit only card $(10.4 \%)$; the remainder pay privately for GP visits. ${ }^{10}$ GPs are critical to managing the increasing amount of chronic illnesses such as heart diseases, diabetes and asthma $-80 \%$ of all visits to the GP are for chronic care management. ${ }^{11}$ In 2015, the first step towards universal healthcare in Ireland was taken when children under 6 years old and adults over 70 years old became eligible for free GP care. ${ }^{11}$ Patients in the latter group accounted for $25 \%$ of GP consultations and $31 \%$ of practice nurse visits in 2016. ${ }^{12}$ Before the start of this pandemic, GPs faced a heavy workload managing the majority of care needs, ${ }^{11}$ completing more than 25 consultations daily, and additional time spent on administration led to GPs working nearly 10 hours in a day. ${ }^{13}$ The need to move more care into the community is the central point of the current healthcare strategy in Ireland. ${ }^{14}$ Another key point in the reform strategy is to achieve universal healthcare by expanding current entitlements and moving to a preventative care model. ${ }^{11}$

With the onset of COVID-19, the face of general practice in Ireland, as in many countries, drastically changed, with developing clinical models ${ }^{15}$ and new consultation strategies having an impact on primary care. ${ }^{16}$ GPs quickly noticed a decrease in the number of appointments scheduled by patients, while practice costs increased and income decreased. ${ }^{17}$ Continuity of routine care might be at risk because of the pandemic, and the general health of the population is a key concern for primary care. ${ }^{16}$ This paper reports on the changes experienced, particularly those in consultation delivery methods, in Irish general practice during the COVID-19 pandemic. At the beginning of February 2020, the Irish College of General Practitioners (ICGP) surveyed its membership before the global pandemic reached Irish shores. In June 2020, the ICGP again surveyed its membership regarding the impact of COVID-19 on general practice.

\section{METHODS}

In early 2020, the ICGP - the professional body for GPs in Ireland-designed an online survey to capture practice activities, stressors and demographic details regarding general practices in Ireland. The survey was developed in order to measure general practice activity, as this information is not yet routinely collected in Ireland. It was the intention to periodically repeat the survey with ICGP members to build a dataset to enable better resource planning in primary care; however, because of the COVID-19 pandemic, a decision was taken to adjust the survey accordingly.

It was distributed to 3,378 members both before (February 2020) and during (June 2020) the coronavirus pandemic. It was not sent to trainees, retired GPs, or Irish GPs working abroad. The second survey was updated to include additional questions and response categories that specifically related to the pandemic. Before each survey was sent out, eight GPs piloted the survey. A population survey approach was taken; therefore, no additional sampling techniques were used. The responding sample was self-selecting, with the survey open for a 2-week period to maximise the number of responses received.

The questionnaire was developed specifically for use in the survey. The questionnaire before the pandemic had 14 items, which covered the number of GPs and practice nurses, consultation activity and hours worked, stressors and practice demographic information. The questionnaire conducted during the pandemic had 25 items, as it gained new items pertaining to changes introduced because of COVID-19. The surveys have been included as online supplemental files 1 and 2, respectively. Questions regarding stress, hours worked, appointment availability and pandemic response were included to obtain a better understanding of the state of general practice.

There were no eligibility criteria to complete the survey. Only one survey for each practice was requested in order to obtain cross-sectional data from Irish general practice. The online survey was fully anonymous and no IP addresses were collected.

All data are based on survey responses. Consultation rates include face-to-face consultations, telephone and video consultations (referred to as telemedicine), home visits and visits to nursing homes reported by practices who responded to the survey. Data were returned regarding the most recent working day. Out-of-hours services in Ireland are provided and recorded separately and hence are not included in these figures. The definitions for city, town and village are based on Central Statistics Office ${ }^{18}$ definitions-rural is an area where less than 1,500 people live, a town has a population between 1,500 and 49,999, and cities have a population 50,000 or more.

We conducted the analysis using SPSS V.25 software, using descriptive analysis. For numerical data, means and medians were used to describe and compare the data as appropriate. A $\mathrm{p}<0.05$ was used to indicate statistical significance. Mann-Whitney U tests were used to compare the number of consultations per GP or practice nurse 
per day; IQR of the median number of consultations are given to show variance within the numbers at each time point and $\chi^{2}$ tests were used for categorical variables.

\section{RESULTS}

\section{Survey population}

There were 526 responses to the pre-COVID-19 survey$32 \%$ of all 1,635 practices in Ireland. ${ }^{19}$ Five hundred and twenty-three practices responded regarding the number of full time equivalent (FTE) GPs employed at the practice, stating that 1,504.5 FTE GPs are employed at these practices. In terms of the number of FTE GPs working on the day on which consultation data is based, 526 practices reported a total of 1,253.9 FTE GPs $(82.8 \%)$ on duty on the day. In this sample, approximately one-fifth $(19.4 \%)$ of the practices had 1.0 FTE GP or less employed-these are considered single-handed practices. The average number of FTE GPs at group practices was 3.3. At least one parttime practice nurse was employed across 483 practices, $93.8 \%$ of the 515 practices who responded to this question. A total of 629.5 FTE practice nurses were employed by these practices. On average, practices employed 1.2 FTE practice nurses -although 161 practices employed between 0.20 and 0.90 FTE practice nurses. In terms of nurses on duty on the day relevant to consultation data, 514 practices reported that 535.8 FTE practice nurses were working across 447 practices. There was an average of 1.0 FTE practice nurse working at each practice; 67 practices stated they had no practice nurses working on the day in question.

In terms of practice location, city practices comprised $37.5 \%$ of the total, with $43.9 \%$ of practices located in towns and $18.6 \%$ in villages. There was at least one practice recorded in every county of Ireland.

In the survey issued during the COVID-19 response, 783 practices responded, however, 240 participants only answered the first four items and five respondents did not consent for their responses to be used-ergo 538 valid responses were received. Hence, $32.9 \%$ of all practices in Ireland were represented in the during COVID-19 survey.

With regard to the total number of FTE GPs and practices nurses employed, 537 practices responded to the GP part of the question reporting 1,276.5 FTE GPs employed overall and 526 practices responded to the practice nurse part of the question, reporting a total of $607.2 \mathrm{FTE}$ nurses. Just 56 practices had no practice nurse employed, and 12 did not respond to this question. With respect to the number of FTE GPs and practice nurses working on the day when consultation numbers were recorded, 534 practices reported that $1,104.9$ FTE GPs were working with an average of 2.1 FTE GPs at working each practice and 513 practices reported 509.0 FTE practice nurses were available, with an average of 1.0 FTE nurse working per practice.

There were slightly more single-handed practices in this responding sample at just over a quarter $(29.0 \%)$. Group practices employed an average of 2.9 FTE GPs.
A total of 537 practices provided location information. City practices comprised $34.4 \%$ of the total, with $46.0 \%$ of practices located in towns and $19.5 \%$ in villages and at least one practice responding in every county. Practice characteristics from both surveys are shown in table 1 .

In both surveys, practices received the questionnaire via email with one additional reminder email. The number of practices that provided valid responses, defined as providing information for overall and on the day data, was comparable. The geographical spread of the practices was similar, though there was a small increase in singlehanded practices responding to the during COVID-19 survey; however, this did not have a significant impact when comparing consultation methods.

In the pre-COVID-19 survey, the proportion of missing responses ranged from $0.6 \%$ to $10.5 \%$, the questions that had more missing responses were the number of consultations completed by practice nurses, with $6.8 \%$ and $10.5 \%$ of practices skipping these questions.

The proportion of missing answers ranged from $1.1 \%$ to $56.7 \%$ in the during COVID-19 survey. The questions that had missing answers were the financial questions, items $8-11$, with a range of $4.5 \%-56.7 \%$ practices not answering these questions.

\section{Consultations}

In the survey pre-COVID-19, items 5, 7 and 8 on the questionnaire (see online supplemental file 1) asked the number of consultations GPs and practice nurses completed in person, using telemedicine and in visits to homes and nursing homes. Overall, 36,821 GP consultations were recorded by 523 practices; $87.3 \%$ of appointments occurred face to face, $10.5 \%$ were telemedicine and the remainder were visits to homes and nursing homes.

During COVID-19, items 21-24 on the questionnaire (see online supplemental file 2) asked practices to report the number of GP and practice nurse consultations completed in person, using telemedicine and in visits to homes and nursing homes. The main mode of consultation changed significantly. This time, 530 practices reported 25,596 consultations. Over half of the GP consultations occurred via telemedicine $(57.0 \%)$ and $41.0 \%$ occurred face to face with the remaining visits to homes or nursing homes. Table 2 shows the proportion of consultations by each consultation method for GPs and practice nurses at each time point.

Face-to-face appointments decreased from $87.3 \%$ to $41.0 \%$ of all GP consultations and consultations by telemedicine increased from $10.5 \%$ to $57.0 \%$ of reported consultations. Before the start of the pandemic, $12.5 \%$ of all consultations (by GPs and practice nurses) were conducted via telemedicine compared with $51.0 \%$ after the pandemic began.

Pre-COVID-19, 490 practices reported that practice nurses completed 13,853 consultations. Just under one-fifth, $17.6 \%$, of practice nurse consultations were via telemedicine and $82.4 \%$ were face to face. During 
Table 1 Practice characteristics

\begin{tabular}{|c|c|c|}
\hline & Pre-COVID-19 & During COVID-19 \\
\hline Total no of practices & 526 & 538 \\
\hline No of single-handed practices & 101 & 156 \\
\hline No of group practices & 422 & 382 \\
\hline Per cent of total & $80.2 \%$ & $71.0 \%$ \\
\hline No of respondents & 523 & 537 \\
\hline Mean GPs overall: & 2.9 & 2.4 \\
\hline No of FTE GPs on the day & 1253.9 & 1104.9 \\
\hline No of respondents & 526 & 534 \\
\hline Mean GPs on day: & 2.40 & 2.1 \\
\hline No of FTE PNs overall & 629.5 & 607.2 \\
\hline No of respondents & 515 & 526 \\
\hline Mean PNs overall: & 1.2 & 1.2 \\
\hline No of FTE PNs on the day & 535.8 & 509.0 \\
\hline No of respondents & 514 & 513 \\
\hline Mean PNs on day & 1.0 & 1.0 \\
\hline Practices located in a city & 197 & 185 \\
\hline Per cent of total & $37.6 \%$ & $34.4 \%$ \\
\hline
\end{tabular}

FTE, full-time equivalent; GP, general practitioner; PN, practice nurse.

the pandemic, 489 practices reported 8,736 practice nurse consultations. The consultations via telemedicine made up $32.4 \%$, with the remainder conducted face to face $(67.6 \%)$.

Before the pandemic began, practice nurses had a higher proportion of telemedicine appointments than GPs - $17.6 \%$ of practice nurse appointments in February 2020 compared with only $10.5 \%$ of GP appointments. During COVID-19, $57.0 \%$ of GP appointments occurred via telemedicine compared with $32.4 \%$ of practice nurse appointments. The Mann-Whitney $U$ test was used to compare GP consultations per day for each consultation method pre-COVID-19 and during COVID-19; all of the tests showed the difference was statistically significant $(\mathrm{p}<0.001)$. The same technique was used to compare the number of consultations by practice nurses per day; this also found that the difference between preCOVID-19 and during COVID-19 nurse consultations was statistically significant $(p<0.001)$. For GPs, the median number of face-to-face consultations went from 26 (IQR 21.3-30) to a median of 8 (IQR 6-13)which was a significant decline $(p<0.001)$. Similarly, GP consultations via telemedicine increased from a median of 2.4 (IQR 0-5.3) to a median of 11.3 (IQR $6-19)$-again this was a significant change $(p<0.001)$. Furthermore, the differences pre-COVID-19 and during the initial COVID-19 response for other consultation methods were all highly significant $(\mathrm{p}<0.001)$.

Practices were asked in the during COVID-19 survey if they had noticed a decline in certain high traffic patient groups. Overall, there was a reported decline in non-COVID-19 related consultations. Five hundred and twenty-six practices answered this question; the question was in tick-box format and practices could select any number of the options. Almost all practices-484 practices $(92.0 \%)$-noticed a decline for children under 6 years old and 418 (79.5\%) saw a decline for patients over 70 years (two patient groups with free GP care nationally). 
Table 2 Summary of consultations

\begin{tabular}{|c|c|c|}
\hline Consultation method & Pre-COVID-19 Consultations & During COVID-19 consultations \\
\hline \multicolumn{3}{|l|}{ GP face- to face } \\
\hline Total consultations & 32160 & 10484 \\
\hline Proportion of GP consultations & $87.3 \%$ & $41.0 \%$ \\
\hline No of respondents & 523 & 530 \\
\hline \multicolumn{3}{|l|}{ GP telemedicine* } \\
\hline Total consultations & 3856 & 14588 \\
\hline Proportion of GP consultations & $10.5 \%$ & $57.0 \%$ \\
\hline No of respondents & 508 & 523 \\
\hline \multicolumn{3}{|l|}{ GP home visits } \\
\hline Total consultations & 483 & 299 \\
\hline Proportion of GP consultations & $1.3 \%$ & $1.2 \%$ \\
\hline No of respondents: & 510 & 517 \\
\hline \multicolumn{3}{|l|}{ GP nursing home visits } \\
\hline Total consultations & 322 & 225 \\
\hline Proportion of GP consultations & $0.9 \%$ & $0.9 \%$ \\
\hline No of respondents & 496 & 503 \\
\hline \multicolumn{3}{|l|}{ PN face to face } \\
\hline Total consultations & 11417 & 5908 \\
\hline Proportion of PN consultations & $82.4 \%$ & $67.6 \%$ \\
\hline No of respondents: & 490 & 489 \\
\hline \multicolumn{3}{|l|}{ PN telemedicine ${ }^{\star}$} \\
\hline Total consultations & 2436 & 2828 \\
\hline Proportion of PN consultations & $17.6 \%$ & $32.4 \%$ \\
\hline No of respondents & 471 & 469 \\
\hline
\end{tabular}

*Telemedicine consultations include video, telephone and other remote technology used.

GP, general practitioner; PN, practice nurse.

\section{Practice income impact}

When practices were asked whether there had been a change in profitability since the pandemic started, 536 practices responded and $80.0 \%$ of these practices reported a decrease in profitability. This was reported by 124 single-handed practices and 305 group practices. These practices estimated they would have a $35.1 \%$ decrease in profitability on average. However, only 257 practices said they had completed a formal assessment of their profits.

More group practices completed formal account reviews assessing the change in practice income and profit-out of the 257 who had completed a formal assessment, 210 were group practices compared with just 47 single-handed practices. Single-handed practices estimated an average loss of $41.5 \%$, compared with the average estimate of $32.6 \%$ for group practices. The lower number of formal assessments by singlehanded practices could explain part of this difference, through overestimates by GPs when completing the survey.
When asked what, if any, assistance measures to help the business manage the financial impact of COVID19 , had been put in place, $308(57.9 \%)$ practices implemented one or more of the changes listed to accommodate for any lost profit. The most popular cost-saving measure used was asking staff to take their annual leave early, with $27.1 \%$ of practices implementing this measure.

There were no significant relationships between practice size and implementing the listed measures.

Overall, 233 practices $(43.3 \%)$ indicated they had staff that were affected by reduced hours, salary or redundancy. The most affected staff has been receptionists with $103(19.1 \%)$ practices recording that this group had been affected in their practice. Following that, were nurses and salaried GP with 83 practices (15.4\%) noting each of these staff groups had been affected. Forty-six GP respondents left comments as well, most highlighting that they had been the one to reduce their personal salary for the sake of keeping their staff. Table 3 shows the proportion of practices 
Table 3 Measures introduced to help the business manage the financial effects of COVID-19

\begin{tabular}{lll} 
& Single-handed practices $(\mathbf{n = 1 5 6 )}$ & Group practices $(\mathbf{n = 3 8 2})$ \\
\hline Have informed staff to take annual leave early & Total: 22 & Total: 124 \\
& Proportion: $14.1 \%$ & Total: 56 \\
Have asked staff to reduce their hours and work them back up & Total: 12 & Proportion: $14.7 \%$ \\
later in the year & Proportion: $7.7 \%$ & Total: 76 \\
Have formally reduced staff hours and payment until & Total: 16 & Proportion: $19.9 \%$ \\
profitability improves & Proportion: $10.3 \%$ & Total: 37 \\
Have made staff redundant & Total: 15 & Proportion: $9.7 \%$ \\
Have applied for the employer wage subsidy scheme & Proportion: $9.6 \%$ & Total: 63 \\
& Proportion: $9.6 \%$ & Proportion: $16.5 \%$
\end{tabular}

that used the following methods to protect income during the pandemic.

\section{DISCUSSION}

\section{Principal findings}

A shift to telemedicine was observed from $10.5 \%$ of all GP consultations and $17.6 \%$ of practice nurse consultations pre-COVID- 19 to $57.0 \%$ and $32.4 \%$, respectively during the COVID-19 response.

More than half of practices saw decreases in nonCOVID-19 related consultations from vulnerable patient groups. Particularly, non-COVID-19-related visits from patients under 6 and over 70-who receive free GP care-decreased despite usually being frequent users of health services.

Finally, practices' finances have been impacted, with $80.0 \%$ reporting reduced profit. Moreover, two-fifths of practices had staff affected by redundancy, reduced hours or reduced salary as a measure to offset the financial impact of the pandemic.

\section{Strengths and weaknesses of the study}

Our surveys are based on a self-selecting sample, which comes with inherent bias. We cannot undertake a direct practice-based pre and post comparison; however, key comparisons indicated that the responding samples were generally comparable. As the study design used a cross-sectional survey approach, a key limitation was the inability to determine causal relationships between the surveys. Due to the changing atmosphere caused by COVID-19, the survey questions were updated and the second iteration was longer-this difference may have caused response bias. Furthermore, we did not collect information that would allow for meaningful geographical analyses, and therefore, could not account for regional and socioeconomic differences, which could affect consultation methods. Data are based on reported data and not from data extracted from general practice systems and hence may lead to under-reporting or over-reporting. The survey was completed by one GP per practice, which could have reduced the accuracy of practice nurse consultation figures, although practice management systems allow identification of these. Additionally, we did not collect patient population information so adjustment for disability or other patient factors could not be undertaken or compared nationally. Finally, the results assume that the national picture corresponds with that of this sample of GP practices.

However, a strength of these surveys is the number of practices and FTE GPs represented. In the pre-COVID-19 survey, there were 1,504.5 FTE GPs represented, employed by the 523 responding practices. In the post-COVID-19 survey, 1,276.5 FTE GPs from the 537 responding practices were represented. This means an estimated $32 \%$ and $33 \%$, respectively, of all practices in Ireland were captured in each survey. While this is a reasonable response rate, it is not a majority of practices; therefore, the proportion of each consultation method is an estimate and should be considered as such in a national context.

Another strength is that the representation of both single-handed and group practices was similar to national figures $^{20}$ making the response more generalisable. And, while detailed geographical information was not collected, both samples included at least one practice in all parts of the country with more in cities such as Dublin and Cork, which is consistent with the geographical spread of practices previously reported. ${ }^{21}$

\section{Interpretation in terms of international literature/strengths and weaknesses compared with other literature}

Since the beginning of the COVID-19 pandemic, there have been many changes rapidly implemented in healthcare across the world and they are having an impact on clinicians. ${ }^{16} 17$ Our study showed a decrease overall in general practice appointments (GPs and practice nurses) in the early days of the pandemic. This is similar to reports in the UK, ${ }^{22}$ where the National Health Service has noticed a $30 \%$ decrease in the number of GP appointments compared with the same time in 2019.

Our study showed a substantial shift from $12.4 \%$ to $50.7 \%$ of GP and practice nurse consultations in Ireland delivered via telemedicine. The UK reports are varied; however, they show a similar shift to telemedicine consultations. With an overall 30\% drop in all consultations, 
GPs reported consultations changing from $90 \%-95 \%$ face to face to $85 \%$ remote. ${ }^{22}{ }^{23}$ The current UK estimates are higher than ours; however, their telemedicine rate pre-COVID-19 was also higher. ${ }^{22}$ Spain also reports an increase in the use of virtual consultations, at $68.3 \%$ during the pandemic. ${ }^{24}$ The proportion of face-to-face GP consultations decreased from $87.3 \%$ to $41.0 \%$ in our study, showing a similar reduction to England where proportions changed from $70 \%$ to $23 \% .^{25}$

The majority (80.0\%) of our practices reported reduced practice profit, and this has been seen elsewhere with GPs in the USA turning to crowdfunding to help their practices, and GPs in Belgium and Australia also feeling the effects of changing remuneration during COVID-19. ${ }^{16} 1726$

Similar studies comparing the impact of COVID-19 on practice consultations are rare. Much of the literature to date on delivery type changes are based on commentaries and not actual measurements. ${ }^{24}{ }^{27}$ However, there are a handful of recent publications about the use of healthcare during the pandemic. A recent German study with 1,095 GPs and patients aged 65 or older found that there was a $14 \%$ decrease in consultations in May 2020 compared with the same time in 2019, and the rate of diabetes, dementia, depression, cancer and stroke diagnoses decreased during this period (between $-17 \%$ and $-26 \%) .{ }^{28}$ In a survey of Australian GPs, $73 \%$ of practices had a reduction in bookings and $77 \%$ had a decrease in practice income; meanwhile, telephone calls (93\%) and practice costs $(81 \%)$ increased. ${ }^{17}$ These results support our survey's findings that these challenges have also been experienced by GPs in Ireland. A key strength of this paper is that it adds to the knowledge base in terms of the potential impact of the COVID-19 pandemic on general practice in the current void of such literature.

\section{Implications for practice}

GPs are motivated by altruism to work during pandemics despite the high personal risk, and they are enthusiastic about further training and information. ${ }^{5}$ However, despite preparedness planning, implementing pandemic policies faces multiple obstacles. ${ }^{5}$ GPs are facing rapidly changing patient flows, clinical algorithms, new care pathways and the need for new ways of delivering highquality care. ${ }^{16} 172427-29$ Irish GPs have implemented many changes during the COVID-19 pandemic. The RACGP recommends 'a planned and coordinated approach' when implementing a telehealth service ${ }^{30}$; however, due to the urgent nature of the current situation, this has not been possible. Maintaining the quality of healthcare is important in sustaining a healthy workforce, which is essential to support a healthy economy during and after the pandemic.

Ireland, like many other countries, has taken massive steps towards the regular use of remote consultations, seemingly overnight, with previous trepidation regarding continuity of care and safety falling away out of necessity. ${ }^{1629}$ The rapid national adoption of telemedicine consultations as well as electronic prescribing has presented opportunity; however, GPs are concerned that without as much face-to-face contact, critical non-verbal communication is missing from consultations and in some cases, telephone consults are insufficient to address patient concerns. ${ }^{16}$

Ireland has two health strategies promoting the use of technology to enable patient-centred care nationally. Sláintecare, the current healthcare strategy in Ireland, aims to establish a national health fund that will help deliver universal healthcare and introduce comprehensive eHealth infrastructure. ${ }^{11}$ This strategy supported the 2013 eHealth strategy, which had an objective of more affordable and more personalised care for all by capitalising on technology. ${ }^{31}$ During the pandemic, practices across the country have swiftly transitioned to using technology such as a secure email facility between healthcare providers (Healthmail), e-prescribing and telemedicine (video and telephone) consultations. Before the COVID-19 pandemic began, clinicians in primary care had used telemedicine interventions, ${ }^{29}$ but not extensively. Changes adopted during this pandemic accelerated the digitalisation of healthcare. ${ }^{29}$ This could lead the way to the lasting adoption of technology such as e-prescribing and telephone and video consultations after the pandemic.

Telemedicine has been viewed as a way to lower costs and see more patients ${ }^{32-34}$ but was rare in Irish general practice up to now, and here, as elsewhere, there was some resistance and concern. ${ }^{16}$ However, the current COVID-19 pandemic has resulted in telemedicine consultations being recommended for all GPs. ${ }^{4}$ Patients, like healthcare workers, have adapted to telemedicine consultations being the standard method of consultation; previous studies found that patients found video consultations acceptable ${ }^{32}$ but age (over 60) and computer proficiency were found to negatively impact a patient's view of acceptability. ${ }^{33}$ Telemedicine has been invaluable during the outbreak of COVID-19, as it has enabled routine care to continue to some degree; however, patients who are digitally disadvantaged are often from populations already experiencing greater health risks-such as older people and those in lower socioeconomic classes. ${ }^{32}$ Going forward, special attention must be given to reducing health inequalities exacerbated by recent changes in care.

Furthermore, a noted decrease in consultations for non-COVID related symptoms has been observed in our survey. Patients who are most vulnerable, such as people over 65, have also been avoiding seeking care in other countries. ${ }^{162628}$ This could have serious impacts on health outcomes and patient safety with calls on patients not to self-diagnose or delay seeking treatment. ${ }^{162628}$ Patients are also changing the way they use health services, with more emphasis on self-care. ${ }^{162428}$ However, not all patients will have the same capacity for caring for their health without the level of support a GP or practice nurse can provide with face-to-face consultations. More research on patient and physician satisfaction and whether health outcomes are impacted by consultation types is needed to develop 
guidelines and policies on how frequently remote consultations can be used. Patient feedback will be invaluable for maintaining lasting benefits.

The COVID-19 pandemic has the potential to change general practice forever, and this does not only apply in Ireland but has been noted elsewhere. ${ }^{15-17} 222428$ The adoption of 'total triage' systems has been seen during this pandemic whereby GPs can decide the mode of follow-up consultation, whether that is face to face, video call or telephone. As we look to a post-COVID landscape, there is a case for general practice retaining this to allow more flexibility in how consultations are delivered according to the needs and preferences of patients. However, telephone triage does not reduce GP workload, so we need to evaluate the impacts on workload and patient-centred care. ${ }^{1632-34}$ While it is unlikely that we will maintain this level of telemedicine consultations, it is expected that how general practice functions will not return to as it was before. ${ }^{29} 35$

However, we should not lose sight of the relationship between the GP and patient and the importance of good communication and trust. ${ }^{1626272932} 33$ Telemedicine does not work for all patients or health problems, and there is a need to establish what works best for different patients. ${ }^{16} 27$ 32-34 We need to evaluate the impact on patient experience, health inequalities and patientcentred care. $^{33} 36$

Since the beginning of June 2020, renewed efforts have been made to reassure and encourage the public to continue seeking medical advice from their GPs by making an appointment. ${ }^{36}$

\section{Unanswered questions and future research}

How general practice is delivered will not return to as before; increased telemedicine is likely. It is necessary to assess the impact of this shift on patient health and to assess healthcare provider and patient experience to ensure continued high-quality care and patient safety. Furthermore, we need to understand the impact of changing work requirements and evolving consultation techniques on general practice workload and practice income and viability.

Correction notice This article has been corrected since it was first published. The formatting of table 2 has been updated.

Acknowledgements The authors wish to acknowledge the valuable contribution and time given by all participants. Dr Jean Saunders, affiliated with CSCS Ireland, statistical advice on the paper is noted and appreciated. We would like to acknowledge and thank Gillian Doran,Patricia Patton, and, Colleen O'Neil for their help with referencing and proofreading this article.

Contributors CC was the project principal investigator. She conceived the project idea, designed the questionnaire, undertook the data collection, obtained the funding, supervised the data analysis and contributed to the paper. RH was the project research assistant. She undertook the analysis and contributed to the paper. Both authors have read and approved the final paper. Name of guarantor: CC.

Funding The project was in part supported via a Quality Improvement Grant from Pfizer under its Global Medical Grants (reference \#6216072).

Disclaimer The funder had no role in project design, data collection, analysis, interpretation or reporting.
Competing interests All authors have completed the Unified Competing Interest form (available on request from the corresponding author) and declare: no financial relationships with any organisations that might have an interest in the submitted work in the previous three years, no other relationships or activities that could appear to have influenced the submitted work.

Patient consent for publication Not required.

Ethics approval Ethical approval from the ICGP Research Ethics Committee for both surveys was obtained and consent from practices for participation and data processing was confirmed at the start of each survey.

Provenance and peer review Not commissioned; externally peer reviewed.

Data availability statement Data are available on reasonable request.

Supplemental material This content has been supplied by the author(s). It has not been vetted by BMJ Publishing Group Limited (BMJ) and may not have been peer-reviewed. Any opinions or recommendations discussed are solely those of the author(s) and are not endorsed by BMJ. BMJ disclaims all liability and responsibility arising from any reliance placed on the content. Where the content includes any translated material, BMJ does not warrant the accuracy and reliability of the translations (including but not limited to local regulations, clinical guidelines, terminology, drug names and drug dosages), and is not responsible for any error and/or omissions arising from translation and adaptation or otherwise.

Open access This is an open access article distributed in accordance with the Creative Commons Attribution Non Commercial (CC BY-NC 4.0) license, which permits others to distribute, remix, adapt, build upon this work non-commercially, and license their derivative works on different terms, provided the original work is properly cited, appropriate credit is given, any changes made indicated, and the use is non-commercial. See: http://creativecommons.org/licenses/by-nc/4.0/.

\section{ORCID iDs}

Robyn Homeniuk http://orcid.org/0000-0002-5526-4113

Claire Collins http://orcid.org/0000-0001-8967-5159

\section{REFERENCES}

1 WHO Newsroom. Timeline of WHO's response to COVID-19. Geneva: World Health Organisation, 2020. https://www.who.int/china/news/ detail/09-01-2020-who-statement-regarding-cluster-of-pneumoniacases-in-wuhan-china

2 WHO. WHO statement regarding cluster of pneumonia cases in Wuhan, China. Geneva: World Health Organisation, 2020. https:// www.who.int/china/news/detail/09-01-2020-who-statementregarding-cluster-of-pneumonia-cases-in-wuhan-china

3 WHO. WHO director-general's statement on IHR emergency committee on novel coronavirus (2019-nCoV. Geneva: World Health Organisation, 2020. https://www.who.int/dg/speeches/detail/whodirector-general-s-statement-on-ihr-emergency-committee-on-novelcoronavirus-(2019-ncov)

4 HSE/HPSC. Guidance on managing risk of transmission of respiratory viruses including COVID-19 in general practice. Dublin: Health Protection Surveillance Centre, 2020. Guidance on minimising risk of transmission in GP practice.pdf (hpsc.ie)

5 Patel MS, Phillips CB, Pearce C, et al. General practice and pandemic influenza: a framework for planning and comparison of plans in five countries. PLoS One 2008;3:e2269.

6 Kunin M, Engelhard D, Thomas S, et al. Challenges of the pandemic response in primary care during Pre-Vaccination period: a qualitative study. Isr J Health Policy Res 2015;4:32.

7 WHO. 2019 novel coronavirus (2019-nCoV): strategic preparedness and response plan. Geneva: World Health Organisation, 2020. https://www.who.int/docs/default-source/coronaviruse/srp04022020.pdf?ua $=1$

8 European Centre for Disease Prevention and Control. Infection prevention and control for COVID-19 in healthcare settings - fourth update. Stockholm: ECDC, 2020. https://www.ecdc.europa. eu/en/publications-data/infection-prevention-and-control-andpreparedness-covid-19-healthcare-settings

9 NPHET. National public health emergency team (NPHET) COVID-19 subgroup: guidance and evidence synthesis. Dublin: Department of Health, 2020. https://www.gov.ie/en/collection/07d750-nphet-covid19-subgroup-guidance-and-evidence-synthesis/

10 HSE. Primary care reimbursement service statistical analysis of claims and payments 2019. Dublin: Health Care Executive Primary Reimbursement Service, 2020. https://www.hse.ie/eng/staff/pcrs/ pcrs-publications/annual-report-2019.pdf 
11 Committee on the Future of Healthcare. Sláintecare report. Dublin: Houses of the Oireachtas, 2017. https://assets.gov.ie/165/ 270718095030-1134389-Slaintecare-Report-May-2017.pdf\#page $=1$

12 Department of Health. Sláintecare action plan 2019. Dublin: Department of Health, 2019. https://assets.gov.ie/22606/4e13c790 cf31463491c2e878212e3c29.pdf

13 Crosbie B, O'Callaghan ME, O'Flanagan S, et al. A real-time measurement of general practice workload in the Republic of ireland: a prospective study. Br J Gen Pract 2020;70:e489-96.

14 Department of Health. Health service capacity review 2018 executive report: review of health demand and capacity requirement in Ireland to 2031 - findings and recommendations. London: PA Knowledge Limited, 2018. https://assets.gov.ie/10131/5bb5ff12463345bbac46 5aaf02a2333d.pdf

15 Liu Y, Wang Z, Ren J, et al. A COVID-19 risk assessment decision support system for general practitioners: design and development study. J Med Internet Res 2020;22:e19786.

16 Verhoeven V, Tsakitzidis G, Philips H, et al. Impact of the COVID-19 pandemic on the core functions of primary care: will the cure be worse than the disease? A qualitative interview study in Flemish GPs. BMJ Open 2020;10:e039674-2020-039674.

17 Kippen R, O'Sullivan B, Hickson $\mathrm{H}$, et al. A national survey of COVID-19 challenges, responses and effects in Australian general practice. Aust J Gen Pract 2020;49:745-51.

18 CSO. CSO statistical release: population and migration estimates. Cork: Central Statistics Office, 2019. https://www.cso.ie/en/releases andpublications/er/pme/populationandmigrationestimatesapril2019/

19 HSE. Medical workforce planning: future demand for general practitoners 2015-2025. Dublin: National Doctor Training and Planning, HR Directorate, Health Service Executive, 2015. https:// www.hse.ie/eng/staff/leadership-education-development/met/plan/ gp-medical-workforce-planning-report-sept-2015.pdf

20 O'Kelly M, Teljeur C, O'Kelly F. Structure of general practice in Ireland 1982 - 2015. Dublin: Trinity College Dublin/Irish College of General Practitioners, 2016. https://www.tcd.ie/medicine/public_health primary_care/assets/pdf/structure-of-general-practice-2016.pdf

21 Smith S, Walsh B, Wren M. Geographic profile of healthcare needs and non-acute healthcare supply in Ireland. ESRI research series: 90. Dublin: The Economic and Social Research Institute, 2019. https:// www.esri.ie/system/files/publications/RS90_0.pdf

22 The Health Foundation. How might COVID-19 affected people's ability to see their GP? COVID-19 chart series. London: The Health Foundation, 2020. https://www.health.org.uk/news-and-comment/ charts-and-infographics/how-might-covid-19-have-affectedpeoples-ability-to-see-GP

23 NHS. Letter to: chief executives of all NHS trusts and foundation trusts; CCG accountable Officers; GP practices and primary care networks; providers of community health services; NHS 111 providers. IMPORTANT - FOR ACTION - SECOND PHASE OF NHS RESPONSE TO COVID19. From the Chief Executive Sir Simon Stevens \& Chief Operating Officer Amanda Pritchard. London: NHS, 2020. https://www.england.nhs.uk/coronavirus/wp-content/uploads/ sites/52/2020/04/second-phase-of-nhs-response-to-covid-19-letterto-chief-execs-29-april-2020.pdf

24 Muñoz M-A, López-Grau M. Lessons learned from the approach to the COVID-19 pandemic in urban primary health care centres in Barcelona, Spain. Eur J Gen Pract 2020;26:106-7.

25 RCGP. General practice in the post Covid world: challenges and opportunities for general practice. London: Royal College of General Practitioners, 2020. https://www.rcgp.org.uk/-/media/Files/News/ 2020/general-practice-post-covid-rcgp.ashx?la=en

26 Rubin R. COVID-19's crushing effects on medical practices, some of which might not survive. JAMA 2020;324:321.

27 de Sutter A, Llor C, Maier M, et al. Family medicine in times of 'COVID-19': a generalists' voice. Eur J Gen Pract 2020;26:58-60.

28 Michalowsky B, Hoffmann W, Bohlken J, et al. Effect of the COVID-19 lockdown on disease recognition and utilisation of healthcare services in the older population in Germany: a crosssectional study. Age Ageing 2021;50:317-325.

29 Marshall M, Howe A, Howsam G, et al. COVID-19: a danger and an opportunity for the future of general practice. $\mathrm{Br} J$ Gen Pract 2020;70:270-1.

30 RACGP. Implementation guidelines for video consultations in general practice: a telehealth initiative. 3rd edition. East Melbourne Victoria: The Royal Australian College of General Practitioners, 2012. https:// www.racgp.org.au/download/Documents/Telehealth/videoconsult guidelinesv3.pdf

31 HSE/Department of Health. eHealth strategy for Ireland. Dublin: Department of Health, 2013. https://www.gov.ie/en/publication/ 6b7909-ehealth-strategy-for-ireland/

32 Thiyagarajan A, Grant C, Griffiths F, et al. Exploring patients' and clinicians' experiences of video consultations in primary care: a systematic scoping review. BJGP Open 2020;4. doi:10.3399/ bjgpopen20X101020. [Epub ahead of print: 0105 2020].

33 Johnston S, MacDougall M, McKinstry B. The use of video consulting in general practice: semi-structured interviews examining acceptability to patients. BMJ Health \& Care Informatics 2016.

34 Gilligan P, Bennett A, Houlihan A, et al. The doctor can see you now: a key Stakeholder study into the acceptability of ambulance based telemedicine. Ir Med J 2018;111:769.

35 Thornton J. Covid-19: how coronavirus will change the face of general practice forever. BMJ 2020;368:m1279.

36 HSE. Coronavirus: get urgent medical help for non-coronavirus symptoms, 2020. Available: https://www2.hse.ie/conditions/ coronavirus/get-urgent-medical-help-for-non-coronavirussymptoms.html 